\title{
BMJ Open Factors associated with work-related burnout in NHS staff during COVID-19: a cross-sectional mixed methods study
}

\author{
Rachel Gemine (1) , ${ }^{1,2}$ Gareth R Davies, ${ }^{1,3}$ Suzanne Tarrant, ${ }^{1}$ Richard M Davies, ${ }^{1}$ \\ Meryl James, ${ }^{1}$ Keir Lewis $^{1,2,3}$
}

To cite: Gemine R, Davies GR, Tarrant S, et al. Factors associated with workrelated burnout in NHS staff during COVID-19: a cross-sectional mixed methods study. BMJ Open 2021;11:e042591. doi:10.1136/ bmjopen-2020-042591

- Prepublication history and additional materials for this paper are available online. To view these files, please visit the journal online (http://dx.doi. org/10.1136/bmjopen-2020042591).

Received 09 July 2020 Revised 10 November 2020 Accepted 30 November 2020

Check for updates

(c) Author(s) (or their employer(s)) 2021. Re-use permitted under CC BY-NC. No commercial re-use. See rights and permissions. Published by BMJ.

${ }^{1}$ Hywel Dda University Health Board, Carmarthenshire, UK

${ }^{2}$ College of Medicine, Swansea University, Swansea, UK

${ }^{3}$ Respiratory Innovation Wales, Llanelli, UK

Correspondence to

Dr Rachel Gemine;

rachel.e.gemine@wales.nhs.uk

\section{ABSTRACT}

Objectives To measure work-related burnout in all groups of health service staff during the COVID-19 pandemic and to identify factors associated with work-related burnout. Design Cross-sectional staff survey.

Setting All staff grades and types across primary and secondary care in a single National Health Service organisation.

Participants 257 staff members completed the survey, 251 had a work-related burnout score and 239 records were used in the regression analysis.

Primary and secondary outcome measures (1) Workrelated burnout as measured by the Copenhagen Burnout Inventory; (2) factors associated with work-related burnout identified through a multiple linear regression model; and (3) factors associated with work-related burnout identified through thematic analysis of free text responses.

Results After adjusting for other covariates (including age, sex, job, being able to take breaks and COVID-19 knowledge), we observed meaningful changes in workrelated burnout associated with having different COVID-19 roles $(p=0.03)$, differences in the ability to rest and recover during breaks $(p<0.01)$ and having personal protective equipment concerns $(p=0.04)$. Thematic analysis of the free text comments also linked burnout to changes in workload and responsibility and to a lack of control through redeployment and working patterns. Reduction in non-COVID-19 services has resulted in some members of staff feeling underutilised, with feelings of inequality in workload.

Conclusions Our analyses support anecdotal reports of staff struggling with the additional pressures brought on by COVID-19. All three of the factors we found to be associated with work-related burnout are modifiable and hence their effects can be mitigated. When we next find ourselves in extraordinary times the ordinary considerations of rest and protection and monitoring of the impact of new roles will be more important than ever.

\section{INTRODUCTION}

SARS-CoV-2 was first encountered in November 2019 and within 7 months had spread around the globe with over 50 million confirmed cases and over 1.2 million deaths by 10 November $2020 .^{1}$

The virus could cause pneumonia-like symptoms, with cases typically presenting
Strengths and limitations of this study

We had responses from a wide range of professionals.

- We surveyed at the height of the pandemic so the results are less prone to recall bias.

- The survey was done in a single institution.

- Free text responses and thematic analysis provided rich opportunity to expand the factors we found were associated with work-related burnout.

- The survey may be open to selection bias.

with coughs, fever and breathing difficulties. At the time of the survey there was no curative treatment for COVID-19 illness. In the absence of vaccination and given its high person-to-person transmissibility, prevention remains reliant on hygiene, personal protective equipment (PPE) and physical separation of people.

As cases increased in our health board the direct impact on the National Health Service (NHS) staff became increasingly apparent. Like other healthcare workers worldwide, new pressures included increased workload, reallocation of duties, adapting to changing needs such as use of PPE and personal/ family risk of infection. This was in addition to usual pressures caused through the virus, self-isolation and social distancing guidelines.

The effect on mental health due to COVID-19 has been documented by the WHO, ${ }^{2}$ including specific messages for healthcare workers regarding stress, increased pressure, stigma and fear.

Staff mental health due to COVID-19 has been assessed worldwide, with research highlighting increased burnout in healthcare professionals and recommendations focusing on reducing burnout in those involved in treating patients with COVID-19. ${ }^{3-5}$ Heavy workloads and physical and emotional load are documented risk factors for burnout. Increased burnout within staff can have an 
impact on personal lives and relationships, and frequent and longer episodes of illness, including increased cardiovascular disease, depression and obesity. ${ }^{6}$ Increased burnout can also lead to reduced quality of care and patient outcomes. ${ }^{7}$ To ensure a psychologically resilient workforce we need to be aware of factors impacting burnout and use preventative strategies. The effects on staff mental health and burnout in the short-term and longer-term need careful evaluation.

We conducted a staff survey to look at burnout and factors impacting staff workload in relation to COVID19, including patient-facing contact. The purpose of the survey was to gain an understanding of stress, burnout and knowledge of COVID-19 across the whole range of health board staff to better enable targeted action.

\section{METHODS}

\section{Population and sample}

The survey targeted the staff population of Hywel Dda University Health Board (http://www.hywelddahb.wales. nhs.uk/) from all grades, both clinical and non-clinical, distinguishing between staff in front-line COVID-19 roles, back office COVID-19 roles and non-COVID roles. The Hywel Dda University Health Board serves 390000 people over a mainly rural location covering Carmarthenshire, Ceredigion and Pembrokeshire, consisting of 4 district hospitals, 11 community hospitals and 53 primary care practices.

\section{Instrumentation}

Staff were asked via work email to complete an online questionnaire (see online supplemental file) using SurveyMonkey from 20 April 2020. The survey consisted of the validated Copenhagen Burnout Inventory $(\mathrm{CBI})^{8}$ and validated Perceived Stress Scale- $10,{ }^{9}$ and three questions were developed to identify perceived knowledge towards COVID-19. By focusing on perceived knowledge, we were able to assess if staff felt adequately informed, regardless of actual knowledge/education.

Work-related burnout is defined within the CBI as 'the degree of physical and psychological fatigue and exhaustion that is perceived by the person as related to his/her work'. ${ }^{8}$ The general interpretation of the CBI scores is that a change or difference of five points is likely to indicate a meaningful difference in the experience of burnout. We also collected age, gender, clinical role, primary or secondary care, and degree of involvement with patients with COVID-19 (front-line COVID-19 roles, back office COVID-19 roles, non-COVID-19 roles). In addition, four questions asked about factors observed or reported to affect staff well-being, mainly regarding PPE and rest and recovery. Respondents were asked to provide additional thoughts on how they were impacted by the pandemic in a free text question to look at indepth views relating to work and burnout.

The survey took around $10 \mathrm{~min}$ to complete.

\section{Patient and public involvement}

The study did not involve patients but was developed in response to staff experiences. Staff were consulted on the survey design. Results will be disseminated to respondents through the local staff communications department via email.

\section{Multiple linear regression analysis}

We developed a linear regression model to understand which factors were associated with work-related burnout. Selection of covariates for the regression model was based on the following process. Four key non-modifiable variables were identified to be retained in the final model, namely age, sex, COVID-19 patient contact and job type. All variables were assessed for collinearity using correlation and cross-tabulations. Where collinearity was present, either the non-key variable was dropped, or if both were non-key variables the one contributing most to the variable inflation factors was dropped. The variable inflation factors were checked again for the resulting model and any variables with values beyond 10 were excluded to form the final model.

The residuals of the final model were plotted against the fitted values and inspected for patterns. The normal probability plot of the standardised residuals was checked for normality.

All variables were fitted as categorical, even where they were ordinal. The model output was presented with all possible pairwise differences for non-ordinal covariates and with only adjacent pairwise differences for ordinal covariates. Overall $\mathrm{p}$ values for the postestimation test for linearity were presented for covariates rather than $p$ values for each pairwise comparison.

Records with missing data were excluded, and all complete records were included. No interactions were considered. Robust SEs were used in the model specification. All analyses were conducted in Stata/IC V.15.1.

\section{Thematic analysis}

All free text responses provided were analysed using the broad principles of thematic analysis ${ }^{10}$ to identify themes relating to burnout. Data were reviewed by an independent researcher to ensure consistency of coding.

\section{RESULTS}

\section{Survey respondents}

The 257 respondents represent around $2.5 \%$ of the total workforce. Although the sample was small, in terms of age, sex and job types the respondents were broadly in line with the total workforce of the health board (table 1). The survey somewhat under-represented the 18-34 age group, nurses and non-clinical staff, and over-represented the 45-54 age group, doctors and other clinical staff. No incentives were offered to staff to undertake the survey.

Despite the low uptake, a broad range of staff roles were seen and demographics were typical of the workforce, indicating generalisability outside of the respondents. 
Table 1 Comparison of survey total with health board total

\begin{tabular}{|llll}
\hline & $\begin{array}{l}\text { Health board } \\
\text { total (\%) }\end{array}$ & $\begin{array}{l}\text { Survey } \\
\text { total (\%) }\end{array}$ & $\begin{array}{l}\text { Model data } \\
\text { set (\%) }\end{array}$ \\
\hline $\begin{array}{l}\text { Age group } \\
18-34\end{array}$ & 28 & & \\
\hline $35-44$ & 22 & 16 & 17 \\
$45-54$ & 28 & 22 & 23 \\
\hline $55+$ & 23 & 39 & 38 \\
\hline Sex & & 23 & 22 \\
\hline Female & 79 & & \\
\hline Male & 21 & 79 & 79 \\
\hline Job & & 21 & 21 \\
\hline Doctor & 7 & & \\
\hline Nurse & 29 & 16 & 17 \\
\hline Other clinical & 6 & 18 & 19 \\
\hline Non-clinical & 58 & 21 & 22 \\
\hline
\end{tabular}

\section{Multiple linear regression analysis}

CBI work-related burnout scores ranged from 3.6 to 96.4 (mean 45.7, SD 15.7), where 0 would be the lowest level of work-related burnout possible and 100 would be the highest possible. ${ }^{3}$

Univariate analyses suggested potentially clinically significant differences (of 5 points or more) between levels of job, COVID-19 role, ability to take a break, quality of breaks when taken, any PPE concerns, COVID-19 knowledge for home life, PPE concerns causing stress, adequacy of PPE and work base (tables 2 and 3 ).

The covariate selection process resulted in all except 'PPE concerns causing stress', 'adequacy of PPE' and 'work base' being retained in the final model. The final model had an $\mathrm{R}^{2}$ of 0.28 . Visual inspections of the plot of the residuals against the fitted values and of the normal probability plot of the standardised residuals did not indicate any systematic issues with the model or any deviation from normality, respectively.

After adjusting for all covariates, only three remained significant predictors of work-related burnout: COVID-19 role $(p=0.03)$, ability to rest and recover during breaks $(\mathrm{p}<0.01)$ and having any concerns about PPE $(\mathrm{p}=0.04)$ (table 4).

Any form of COVID-19 role caused a clinically significant increase in work-related burnout when compared with non-COVID-19 roles. However, the CIs were wide and only the back office COVID-19 roles interval excluded 0 ( $B=6.05,95 \%$ CI 0.94 to 11.16$)$.

The declining ability to rest and recover during breaks led to a fairly constant and clinically significant increase in work-related burnout from category to category, although there were suggestions of a floor effect with the final two groups (seldom and never/almost never) being almost identical. Again, the CIs were wide, and while the changes were large only the change from sometimes to seldom had an interval excluding 0 ( $\hat{B}=6.82,95 \%$ CI 1.68 to 11.97$)$.

Having any concerns about PPE caused an increase in work-related burnout when compared with no such concerns, although this was slightly below the clinical significance threshold and had wide CIs $(\hat{B}=4.02,95 \%$ CI 0.14 to 7.90$)$.

\section{Thematic analysis}

Thematic analysis was conducted on free text responses regarding the impact of COVID-19. There were 257 staff members who provided a response. The majority expressed negative impact on their work and personal lives contributing to burnout; however, some expressed more positive responses in terms of work and the potential for new opportunities, which may be protective in reducing risk of burnout.

Unsurprisingly, considering it was issued to NHS staff, workload and changes to role were a predominant theme. Individuals highlighted concerns over lack of control and consultation on changes to their role, rota or work location.

My rota and role has been completely changed without taking into account my thoughts or preferences, not even asked if I was okay with this.

Concerns over redeployment were also apparent. Lack of choice in work was mentioned in association with feelings of burnout. Poor communication from managers and health board contributed to these feelings, with inconsistent information being circulated. Some stated that they felt undervalued and that they were not trusted to undertake work remotely. Draining, pressure, unfairness and frustration were keywords within the text responses. Perceived lack of support and unfairness were reported.

Possible redeployment is an extremely big concern. Uncertainty of possible redeployment is a big concern. Uncertainty of being moved out of current workplace is a big concern.

Issues with information technology and lack of equipment and training were raised as barriers to efficient working, although home working did allow more flexibility for people. Lack of PPE was also a concern contributing to burnout and impacting well-being, although interestingly in many cases it was concern for lack of PPE for others rather than the individual who responded. In addition, feelings of being vulnerable and insecure at work emerged, with increased risk to healthcare professionals in relation to COVID-19.

Lack of adequate PPE to protect me from Covid19 has resulted in my having to adopt a secondary role in caring for patients, which makes me feel frustrated that I cannot do what I am trained to do, namely care for ill people.

Our analysis has shown a link between burnout and not taking adequate quality breaks, allowing for rest and 
Table 2 Descriptive statistics for variables included in the multiple linear regression model

Total survey $(\mathrm{N}=257)$

\begin{tabular}{|c|c|c|c|c|c|c|c|c|}
\hline \multirow[b]{3}{*}{ Variable } & \multicolumn{4}{|c|}{ Total survey $(\mathrm{N}=257)$} & \multicolumn{4}{|c|}{ Model data set $(n=239)$} \\
\hline & \multirow[b]{2}{*}{$\mathbf{n}$} & \multirow[b]{2}{*}{$\%$} & \multicolumn{2}{|c|}{ CBI work-related stress } & \multirow[b]{2}{*}{$\mathbf{n}$} & \multirow[b]{2}{*}{$\%$} & \multicolumn{2}{|c|}{ CBI work-related stress } \\
\hline & & & Mean & SD & & & Mean & SD \\
\hline \multicolumn{9}{|l|}{ Job } \\
\hline Doctor & 41 & 16 & 49.7 & 17.6 & 40 & 17 & 48.5 & 15.8 \\
\hline Nurse & 46 & 18 & 51.1 & 11.9 & 45 & 19 & 51.1 & 11.9 \\
\hline Non-clinical & 53 & 21 & 46.4 & 17 & 42 & 33 & 46.8 & 16.9 \\
\hline Other clinical & 113 & 44 & 41.5 & 15.4 & 102 & 43 & 41.6 & 15.6 \\
\hline Missing & 4 & 2 & - & - & - & - & - & - \\
\hline \multicolumn{9}{|l|}{ Age } \\
\hline $18-34$ & 42 & 16 & 48.5 & 16.2 & 41 & 17 & 48.9 & 16.2 \\
\hline $35-44$ & 56 & 22 & 43.7 & 17.1 & 55 & 23 & 44 & 17.1 \\
\hline $45-54$ & 101 & 39 & 45 & 15.7 & 91 & 38 & 44.5 & 15.7 \\
\hline $55+$ & 58 & 23 & 46.4 & 15.7 & 52 & 22 & 47 & 13.6 \\
\hline Missing & 0 & 0 & - & - & - & - & - & - \\
\hline \multicolumn{9}{|l|}{ Sex } \\
\hline Female & 201 & 78 & 45.6 & 15.4 & 189 & 79 & 45.9 & 15.3 \\
\hline Male & 52 & 20 & 44.6 & 17.1 & 50 & 21 & 44.9 & 17.2 \\
\hline Missing & 4 & 2 & - & - & - & - & - & - \\
\hline \multicolumn{9}{|l|}{ COVID-19 role } \\
\hline Non-COVID-19 role & 131 & 51 & 41.3 & 15 & 121 & 51 & 41.4 & 14.7 \\
\hline COVID-19 back office & 60 & 23 & 47.9 & 16 & 53 & 22 & 49 & 16.2 \\
\hline COVID-19 front line & 66 & 26 & 51.7 & 16.1 & 65 & 27 & 51 & 15 \\
\hline Missing & 0 & 0 & - & - & - & - & - & - \\
\hline \multicolumn{9}{|c|}{ Able to take a break at work? } \\
\hline Always & 50 & 19 & 42.6 & 17.1 & 47 & 20 & 41.8 & 15 \\
\hline Often & 63 & 25 & 42.2 & 14.2 & 60 & 25 & 42.7 & 14.1 \\
\hline Sometimes & 88 & 34 & 48.2 & 16.3 & 81 & 34 & 48.4 & 16.2 \\
\hline Seldom & 38 & 15 & 47.3 & 14.7 & 34 & 14 & 47.6 & 15.1 \\
\hline Never/almost never & 18 & 7 & 49.2 & 19.3 & 17 & 7 & 50.4 & 19.1 \\
\hline Missing & 0 & 0 & - & - & - & - & - & - \\
\hline \multicolumn{9}{|c|}{ Rest and recover during breaks? } \\
\hline Always & 32 & 12 & 35.3 & 16.7 & 28 & 12 & 34.7 & 15 \\
\hline Often & 67 & 26 & 41.2 & 13.3 & 63 & 26 & 41.4 & 13.5 \\
\hline Sometimes & 84 & 33 & 45.9 & 14.8 & 80 & 33 & 46.1 & 14.8 \\
\hline Seldom & 46 & 18 & 53.6 & 14.6 & 43 & 18 & 54.2 & 14.7 \\
\hline Never/almost never & 28 & 11 & 53.4 & 18.1 & 25 & 10 & 52.9 & 15.9 \\
\hline Missing & 0 & 0 & - & - & - & - & - & - \\
\hline \multicolumn{9}{|l|}{ Any concerns about PPE? } \\
\hline No & 134 & 52 & 42.5 & 15.5 & 127 & 53 & 42.4 & 15.3 \\
\hline Yes & 116 & 45 & 49.5 & 16.1 & 112 & 47 & 49.5 & 15.3 \\
\hline Missing & 7 & 3 & - & - & - & - & - & - \\
\hline \multicolumn{9}{|c|}{ Enough COVID-19 knowledge for work life? } \\
\hline No & 33 & 13 & 48.7 & 17.1 & 30 & 13 & 47.7 & 16.4 \\
\hline Not sure & 47 & 18 & 48.3 & 15.1 & 43 & 18 & 49 & 15 \\
\hline Yes & 175 & 68 & 44.5 & 16.1 & 166 & 69 & 44.4 & 15.7 \\
\hline
\end{tabular}


Table 2 Continued

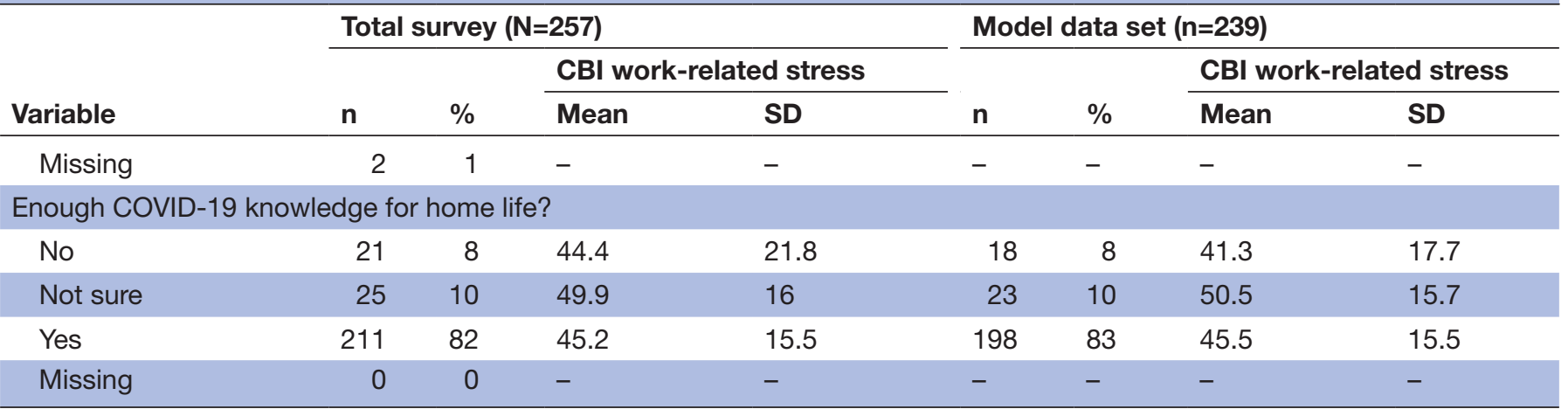

CBI, Copenhagen Burnout Inventory; PPE, personal protective equipment.

recovery. Those who reported often taking breaks did so because they needed to eat or for their well-being. Some reported home working allowed them more flexibility to do this compared with when they were hospital-based.

Being too busy, increased workload and reduced staffing meant people did not take good quality breaks, allowing for adequate rest and recovery. This was accompanied

Table 3 Descriptive statistics for variables not included in the multiple linear regression model

\begin{tabular}{|c|c|c|c|c|}
\hline \multirow[b]{3}{*}{ Variable } & \multicolumn{4}{|c|}{ Total survey } \\
\hline & \multirow[b]{2}{*}{$\mathbf{n}$} & \multirow[b]{2}{*}{$\%$} & \multicolumn{2}{|c|}{$\begin{array}{l}\text { CBI work-relatec } \\
\text { stress }\end{array}$} \\
\hline & & & Mean & SD \\
\hline \multicolumn{5}{|c|}{ PPE concerns affecting stress at work? } \\
\hline Always & 10 & 4 & 66.1 & 22 \\
\hline Often & 36 & 14 & 50.1 & 14 \\
\hline Sometimes & 65 & 25 & 48.5 & 14 \\
\hline Seldom & 48 & 19 & 44 & 12 \\
\hline Never/almost never & 84 & 33 & 40.3 & 17 \\
\hline Missing & 14 & 5 & & \\
\hline \multicolumn{5}{|l|}{ Adequate PPE at work? } \\
\hline Always & 78 & 30 & 42.9 & 17 \\
\hline Often & 55 & 21 & 45.9 & 13 \\
\hline Sometimes & 49 & 19 & 49.1 & 16 \\
\hline Seldom & 14 & 5 & 38.8 & 17 \\
\hline Never/almost never & 42 & 16 & 48.4 & 17 \\
\hline Missing & 19 & 7 & & \\
\hline \multicolumn{5}{|l|}{ Work base } \\
\hline $\begin{array}{l}\text { Clinical/secondary } \\
\text { care }\end{array}$ & 114 & 44 & 45.8 & 15 \\
\hline Clinical/primary care & 58 & 23 & 48.9 & 15 \\
\hline Non-clinical & 70 & 27 & 41.8 & 16 \\
\hline Missing & 15 & 6 & & \\
\hline
\end{tabular}

$\mathrm{CBI}$, Copenhagen Burnout Inventory; PPE, personal protective equipment. by feelings of pressure and guilt to continue working. In addition, the culture of working through has an impact. People stated that they worked through their break or took shorter breaks because others did so, and their managers did not actively encourage their staff to take restorative breaks and there were expectations placed on staff, in some cases, to continue to work.

Feel guilty that I am not doing enough to help with the crisis so don't feel taking a break is a priority.

Lack of staff, high work load.

Just feel I need to keep going as everyone else is.

No time. Too much work pressure from patients and now more commonly LHB/management.

Those in office-based roles particularly reported eating lunch at their computer, with some saying they regularly catch up on emails or take calls as part of their break. Other barriers to taking breaks included lack of places to go to take a break.

...there is nowhere to go for a break. I eat at my desk and carry on working 4 out of the 5 days.

Changes to working relationships were reported frequently. While some mentioned poor communication and negative impact on their team, others cited improved communication and a positive effect leading to improved and strengthened relationships. This seems to stem from those where open discussions regarding changes to work were employed, strong management structure and clear guidelines/information relayed.

In my directorate there seems to be an overall understanding that staff need to be treated with care in a very stressful and unprecedented situation. My head of service in particular is putting staff well being as a paramount.

Feelings of exhaustion and burnout were freely reported in relation to changes placed on them.

Overwhelmed at how tired mentally I have been. 
Table 4 Multiple linear regression model output

\begin{tabular}{|c|c|c|c|c|}
\hline Covariate & & SE & $95 \% \mathrm{Cl}$ & $P$ value \\
\hline Job & & & & 0.16 \\
\hline Doctor vs nurse & -2.82 & 3.20 & -9.13 to 3.48 & \\
\hline Doctor vs other clinical & -0.40 & 3.27 & -6.84 to 6.04 & \\
\hline Doctor vs non-clinical & 2.92 & 3.13 & -3.25 to 9.09 & \\
\hline Nurse vs other clinical & 2.43 & 2.77 & -3.04 to 7.89 & \\
\hline Nurse vs non-clinical & 5.74 & 2.52 & 0.78 to 10.70 & \\
\hline $\begin{array}{l}\text { Other clinical vs non- } \\
\text { clinical }\end{array}$ & 3.32 & 2.85 & -2.29 to 8.92 & \\
\hline Age & & & & 0.23 \\
\hline $35-44$ vs $18-34$ & -4.76 & 2.97 & -10.61 to 1.08 & \\
\hline $45-54$ vs $35-44$ & -0.30 & 2.59 & -5.40 to 4.79 & \\
\hline $55+$ vs $45-54$ & 1.28 & 2.42 & -3.50 to 6.06 & \\
\hline Sex & & & & 0.33 \\
\hline Female vs male & 2.56 & 2.61 & -2.59 to 7.70 & \\
\hline COVID-19 role & & & & 0.03 \\
\hline $\begin{array}{l}\text { COVID-19 front line vs } \\
\text { COVID-19 back office }\end{array}$ & -1.28 & 3.11 & -7.40 to 4.85 & \\
\hline $\begin{array}{l}\text { COVID-19 front line vs } \\
\text { non-COVID-19 role }\end{array}$ & 4.78 & 2.51 & -0.17 to 9.72 & \\
\hline $\begin{array}{l}\text { COVID-19 back office vs } \\
\text { non-COVID-19 role }\end{array}$ & 6.05 & 2.59 & 0.94 to 11.16 & \\
\hline Able to take a break & & & & 0.98 \\
\hline Often vs always & -1.17 & 2.75 & -6.59 to 4.24 & \\
\hline Sometimes vs often & 0.70 & 2.48 & -4.18 to 5.58 & \\
\hline Seldom vs sometimes & -0.98 & 3.17 & -7.23 to 5.28 & \\
\hline $\begin{array}{l}\text { Never/almost never vs } \\
\text { seldom }\end{array}$ & 2.55 & 5.27 & -7.83 to 12.92 & \\
\hline $\begin{array}{l}\text { Able to rest and recover } \\
\text { during breaks }\end{array}$ & & & & $<0.01$ \\
\hline Often vs always & 6.05 & 3.50 & -0.86 to 12.95 & \\
\hline Sometimes vs often & 4.82 & 2.41 & -0.07 to 9.56 & \\
\hline Seldom vs sometimes & 6.82 & 2.61 & 1.68 to 11.97 & \\
\hline $\begin{array}{l}\text { Never/almost never vs } \\
\text { seldom }\end{array}$ & 0.04 & 4.77 & -9.36 to 9.43 & \\
\hline $\begin{array}{l}\text { Have any concerns about } \\
\text { PPE? }\end{array}$ & & & & 0.04 \\
\hline Yes vs no & 4.02 & 1.97 & 0.14 to 7.90 & \\
\hline $\begin{array}{l}\text { Enough COVID-19 } \\
\text { knowledge for work life? }\end{array}$ & & & & 0.54 \\
\hline Yes vs no & -0.67 & 2.53 & -5.66 to 4.32 & \\
\hline Yes vs not sure & -2.90 & 2.61 & -8.05 to 2.25 & \\
\hline No vs not sure & -2.23 & 3.10 & -8.33 to 3.88 & \\
\hline $\begin{array}{l}\text { Enough COVID-19 } \\
\text { knowledge for home life? }\end{array}$ & & & & 0.48 \\
\hline Yes vs no & 2.58 & 3.44 & -4.21 to 9.36 & \\
\hline Yes vs not sure & -2.26 & 2.82 & -7.80 to 3.29 & \\
\hline No vs not sure & -4.83 & 4.02 & -12.75 to 3.08 & \\
\hline Constant & 33.95 & 6.87 & - & \\
\hline
\end{tabular}

PPE, personal protective equipment.
Despite the negative impact on work role, several positives emerged. These included opportunities for increasing and improving skills and services, with the situation allowing people to showcase adaptability and resourcefulness. Working from home was seen by some as enhancing work life balance and potentially protective against burnout.

It has greatly improved my family/work life balance as working hours at [hospital site] have been altered to reduce risk of exposure and spread.

Using technology for working remotely and teaching is a great opportunity.

Adaptability to the current situation has been clear, indicating resilience among staff and commitment to deliver care to patients and colleagues, although the need to adapt has been seen as stressful.

...had to think of new and innovative ways to deliver the service.

Have to adapt to ever changing advice and situation related to covid-19 can be stressful and constant worry if doing all we can to stop spread.

The impact of COVID-19 on the non-COVID-19 population was also apparent, particularly in mental health services and oncology. Lack of care and regular contact for vulnerable groups and lack of clarity about future plans were recurrent themes. Staff felt they were unable to provide the care their patients needed as they were not prioritised, and in several cases staff reported not undertaking duties they had trained for. Several who had been redeployed felt there was not a need for them and that they would be better used in their normal roles. Reduction in workload was visible in several responses.

My job role has slowed down to almost a standstill due to having discharged my entire case load. I question the value of being at work at all because I have almost nothing to do.

While not related to burnout, several respondents reported feelings of guilt due to underutilisation, where they were isolating or redeployed to non-COVID-19 or quieter departments. Some demonstrated concerns about how this could be perceived by their colleagues. In addition, staff reported feelings of isolation, anxiety and depression. The impact on mental health and well-being warrants further exploration.

\section{DISCUSSION}

Through our quantitative and qualitative analyses we can see that staff are at high risk of burnout. If the stress experienced continues, with fatigue becoming more chronic, there are huge implications for the well-being and engagement of staff, as well as for productivity, patient safety and patient outcomes. We have identified a number of factors and themes associated with work-related burnout during 
a pandemic. At least two main factors appear modifiable, suggesting targeting issues such as PPE concerns and meaningful breaks could have real impact on levels of work-related burnout. These could be crucial lessons to be learnt from the COVID-19 pandemic to help maintain NHS services in the event of a similar crisis.

The main strengths of our study are the triangulation of the findings through mixed methods and the transparent description and assessment of the quantitative analysis. Use of qualitative analysis focused on examining and identifying explicit and implicit themes within the data, allowing linking of broader theoretical or conceptual issues relevant to staff burnout. To some extent this overcomes its main weaknesses of self-selection and small sample size. However, the wide CIs suggest larger numbers are needed to validate these findings.

Due to the new and unprecedented nature of the pandemic, there is limited literature assessing burnout in relation to COVID-19. In line with previous research, this study identified similar factors affecting burnout, such as poor quality or ineffective breaks, increased workload and emotional pressures. ${ }^{11} 12$ PPE concerns were consistent with those seen elsewhere, as were issues with management and communication. ${ }^{13} 14$ There is some evidence for increased burnout within staff working directly within COVID-19 wards; however, our sample size here is low, and even in a single health board healthcare settings can vary in structure, for example, between hospitals, reducing generalisability. While we saw an association between working directly with patients with COVID-19 and burnout, this has not been seen elsewhere, with one study showing that those working on front-line COVID-19 wards were less at risk of burnout than those working in general oncology wards. ${ }^{15}$ The specification of wards may have impacted these findings as we did not differentiate between specialties.

We only collected data at one time point, and longitudinal data to map burnout in line with the pandemic would be advantageous. Moreover, the risk of actual burnout, particularly in those who are vulnerable now, may increase over the coming weeks and months. This would be a particular concern as we restart normal services while managing the needs of patients with COVID-19. A prospective and repeating focus on systemic adjustments/recalibrations to prevent the causes of workrelated burnout would be preferable to implementing services retrospectively, after damage has been done which could have been avoided. This is likely to include clear and consistent messages and planning from the NHS and government.

Our research did not look at mechanisms for addressing the issues we identified. Future research to determine optimal ways for sharing, listening and raising concerns, formally as well as informally, would be valuable. Similarly, the development of effective emergency consultation mechanisms for individuals and teams where roles are impacted and for joint decision making, particularly in relation to redeployment, could help reduce work-related concerns. It is essential to learn the lessons from this period if we are to avoid making the same mistakes if, or perhaps when, we are in a similar situation again.

Acknowledgements The authors would like to thank Delyth Evans for creating the electronic survey and extracting the raw data.

Contributors $\mathrm{KL}$ conceived the study. All authors contributed to the survey design. RMD coordinated the data collection process. GRD conducted the statistical analysis. RG conducted the thematic analysis. All authors contributed to the interpretation of the findings with expert input from MJ and ST. GRD and RG drafted the manuscript. All authors approved the final version of the manuscript. The corresponding author attests that all listed authors meet authorship criteria and that no others meeting the criteria have been omitted.

Funding The authors have not declared a specific grant for this research from any funding agency in the public, commercial or not-for-profit sectors.

Competing interests None declared.

Patient consent for publication Not required.

Ethics approval This study was not deemed to be research by the R\&D Department so research ethics committee approval was not needed but was endorsed by senior management.

Provenance and peer review Not commissioned; externally peer reviewed.

Data availability statement Data are available upon reasonable request.

Supplemental material This content has been supplied by the author(s). It has not been vetted by BMJ Publishing Group Limited (BMJ) and may not have been peer-reviewed. Any opinions or recommendations discussed are solely those of the author(s) and are not endorsed by BMJ. BMJ disclaims all liability and responsibility arising from any reliance placed on the content. Where the content includes any translated material, BMJ does not warrant the accuracy and reliability of the translations (including but not limited to local regulations, clinical guidelines, terminology, drug names and drug dosages), and is not responsible for any error and/or omissions arising from translation and adaptation or otherwise.

Open access This is an open access article distributed in accordance with the Creative Commons Attribution Non Commercial (CC BY-NC 4.0) license, which permits others to distribute, remix, adapt, build upon this work non-commercially, and license their derivative works on different terms, provided the original work is properly cited, appropriate credit is given, any changes made indicated, and the use is non-commercial. See: http://creativecommons.org/licenses/by-nc/4.0/.

ORCID iD

Rachel Gemine http://orcid.org/0000-0001-8425-7388

\section{REFERENCES}

1 World Health Organization. Coronavirus disease (COVID-19) pandemic, 2020. Available: https://www.who.int/emergencies/ diseases/novel-coronavirus-2019 [Accessed 10 Nov 2020].

2 World Health Organization. Mental health and psychosocial considerations during the COVID-19 outbreak, 18 March 2020 (NO. WHO/2019-nCoV/MentalHealth/2020.1) 2020.

3 Chen Q, Liang M, Li Y, et al. Mental health care for medical staff in China during the COVID-19 outbreak. Lancet Psychiatry 2020;7:e15-16.

4 Jalili M, Niroomand M, Hadavand F, et al. Burnout among healthcare professionals during COVID-19 pandemic: a cross-sectional study. medRxiv 2020.

5 Khasne RW, Dhakulkar BS, Mahajan HC, et al. Burnout among healthcare workers during COVID-19 pandemic in India: results of a questionnaire-based survey. Indian J Crit Care Med 2020;24:664-71.

6 Salvagioni DAJ, Melanda FN, Mesas AE, et al. Physical, psychological and occupational consequences of job burnout: a systematic review of prospective studies. PLoS One 2017; 12:e0185781.

7 Rees CS, Eley R, Osseiran-Moisson R, et al. Individual and environmental determinants of burnout among nurses. $J$ Health Serv Res Policy 2019;24:191-200.

8 Kristensen TS, Borritz M, Villadsen E, et al. The Copenhagen burnout inventory: a new tool for the assessment of burnout. Work \& Stress 2005; 19:192-207.

9 Cohen S, Kamarck T, Mermelstein R. Perceived stress scale. In: Measuring stress: a guide for health and social scientists. , 1994: 10, 1-2. 
10 Braun V, Clarke V. Using thematic analysis in psychology. Qual Res Psychol 2006;3:77-101.

11 Gavin B, Hayden J, Adamis D, et al. Caring for the psychological well-being of healthcare professionals in the Covid-19 pandemic crisis. Ir Med J 2020;113:51.

12 Tan BYQ, Kanneganti A, Lim LJH, et al. Burnout and associated factors among health care workers in Singapore during the COVID-19 pandemic. J Am Med Dir Assoc 2020;21:1751-8.

13 Sasangohar F, Jones SL, Masud FN, et al. Provider burnout and fatigue during the COVID-19 pandemic: lessons learned from a highvolume intensive care unit. Anesth Analg 2020;131:106-11.
14 Martínez-López José Ángel, Lázaro-Pérez C, Gómez-Galán J, et al. Psychological impact of COVID-19 emergency on health professionals: Burnout incidence at the most critical period in Spain. $J$ Clin Med 2020;9:3029.

$15 \mathrm{Wu}$ Y, Wang J, Luo C, et al. A comparison of burnout frequency among oncology physicians and nurses working on the frontline and usual wards during the COVID-19 epidemic in Wuhan, China. J Pain Symptom Manage 2020;60:e60-5. 